\title{
Crustal strain field in the Deccan trap region, western India, derived from GPS measurements
}

\author{
C. D. Reddy ${ }^{1 *}$, Gamal El-Fiky ${ }^{2}$, Teruyuki Kato ${ }^{1}$, Seiichi Shimada ${ }^{3}$, and K. Vijay Kumar ${ }^{4}$ \\ ${ }^{1}$ Earthquake Research Institute, The University of Tokyo, Tokyo 113-0032, Japan \\ ${ }^{2}$ National Research Institute of Astronomy and Geophysics, Helwan, Cairo, Egypt \\ ${ }^{3}$ National Research Institute for Earth Science and Disaster Prevention, Tsukuba 305-0006, Japan \\ ${ }^{4}$ Department of Environmental Science, Ibaraki University, Mito 310-0903, Japan
}

(Received January 11, 2000; Revised July 6, 2000; Accepted August 31, 2000)

\begin{abstract}
Global Positioning System (GPS) measurements were made to estimate the crustal deformation strain rate for the Deccan trap region, western India. Estimated horizontal velocity vectors in ITRF96 are in the range of 40-60 mm/yr with an average of $51 \mathrm{~mm} / \mathrm{yr}$ in $\mathrm{N} 47^{\circ} \mathrm{E}$. Using the horizontal components of the velocity vectors, strain field has been estimated by the Least Square Prediction (LSP) method. An extension is observed along the west coast and south of Koyna and Warna reservoirs, transcending in to a region of compressive regime towards the interior of the shield area. The west coast geothermal province coincides with the extension regime. The collision between India and Eurasia is likely cause for compression regime. The results are discussed in conjunction with the seismo-tectonics of the study region.
\end{abstract}

\section{Introduction}

The Deccan trap region of western India generally considered as a seismically stable continental region (SCR), has been experiencing significant level of seismicity in the past two decades including the devastating Latur earthquake (M6.3) of 29 September, 1993 (Gupta, 1993; Seeber et al., 1996). This occurrence in the Central Indian shield has led to serious introspection among geo-scientists and motivated the Department of Science and Technology, Government of India, to sponsor the programme 'Seismological upgradation and related studies in peninsular Shield'. Under this programme, to estimate the crustal deformation, a 73 site GPS geodetic network, distributed in an area of $200 \times 350$ $\mathrm{km}^{2}$ (shaded region in the inset of Fig. 1) has been designed. The first campaign started during January, 1995. However, in this study, to get preliminary idea on nature of velocity and strain fields, we have used the GPS data collected from 3 campaigns during 1997-1999 at 21 alternative sites in the selected 73 site GPS network.

Apart from the GPS technique, other geological and geophysical data like earthquake focal mechanisms, well bore breakouts, in-situ stress measurements (hydraulic fracturing and over coring), young geologic data etc. are used to infer the tectonic stress distribution. While giving first and second order lithospheric stress patterns, Zoback (1992) explained these methods. Using borehole breakouts, hydraulic fracturing stress measurements, and earthquake focal mechanisms Gowd et al. (1992) evaluated tectonic stress field for Indian

*Presently on leave from Indian Institute of Geomagnetism, Colaba (P.O), Mumbai 400005, India.

Copy right(c) The Society of Geomagnetism and Earth, Planetary and Space Sciences (SGEPSS); The Seismological Society of Japan; The Volcanological Society of Japan; The Geodetic Society of Japan; The Japanese Society for Planetary Sciences. subcontinent. Their results indicate that, the stress pattern in Indian subcontinent including peninsular shield is being compressionally stressed in a NNE-SSW direction. Using 317 published focal mechanisms (only 7 from Peninsular India) Rajendran et al. (1992) derived the state of stress in the Indian subcontinent. Their results indicated orientation of $\mathrm{S}\left(\mathrm{H}_{\max }\right)$ in Peninsular India in the N-S to NNE-SSW direction.

In India, first GPS measurements were made in 1994 under the South India Strain Measuring Experiment (SISME) (Gaur, 1994) which was mainly designed to determine whether strain related to microseismicity in the past century may have deformed the networks of the 19th century Great Trigonometrical Survey of India (GTS). The SISME results are reported by Paul et al. (1995). During this time an IGS site at the Indian Institute of Science (IISC), Bangalore was commissioned. During 1995, the National Geophysical Research Institute (NGRI), Hyderabad, also started a permanent GPS station. The present study is not a part of SISME.

\section{Regional Tectonics}

The Indian plate region is broadly divided into three regions viz. the Himalayan front in the north, the Indo-Gangetic Plains (IGP) and the Peninsular shield further south. Himalayan orogeny is believed to be a manifestation of collision between India and Eurasia plates. The IGP is a foredeep with alluvium and sediments. South of IGP is the Indian Peninsular shield which is a mosaic of various cratons bordered by paleo-rift valleys. Geological map of India with various cratonic divisions bordered by rift valley zones is given by Goodwin (1991).

The Indian shield is a Stable Continental Region (SCR) with low seismicity level similar to Australian and North American shield regions. Well documented historical earth- 
quake data from 1340 to 1983 has been analysed and reported in Rao and Rao (1984). However, considerable seismic activity has been observed during the last few decades. The Latur earthquake of 29 September, 1993 (Gupta, 1993) is considered to be most devastating SCR earthquake claiming more than 11,000 lives. The most recent one occured on 5 September, 2000 (M5.2, Long. 73.8E, Lat. 17.3N).

One of the most important geological features in the peninsular shield is the Deccan Volcanic Province (DVP) (see Goodwin, 1991; Gowd et al., 1996). A major magmatic event gave rise to the DVP (Naqvi and Rogers, 1987) and is the largest lava flows in the world and spreads to about $500000 \mathrm{sqkm}$. This region is characterised by many hidden tectonic features and complex geophysical signatures. The western margin parallel to the west coast fault and the Panvel flexure axis (Arora and Reddy, 1991) along the west coast, is characterized by high uplift and/or subsidence, relatively large deformation, magmatism, high heat flow and hot springs and considered to be mobile relative to the Dharwar craton (Raval, 1995). Hereafter we refer this zone as West Coast Geothermal Province (WCGP). Madagascar and the Seychelles-Mascarene block may have existed along the west coast before being broken away from the mainland (Singh and Mall, 1998). The earthquakes of this region are primarily intra-plate earthquakes caused by crustal faults and vertical movements of crustal blocks (Kailasam, 1993).

The seismicity of the Indian shield, as evidenced by historical as well as instrumented data indicates that $80 \%$ of intraplate earthquakes are confined to some linear belts, while the remaining are scattered over the rest of the Indian shield (Gowd et al., 1996). One such linear belt is the WCGP which is the most seismically active linear belt in the Indian shield. The Peninsular India has been an area of increased earthquake activity and this activity appears to be increasing from continental nuclei to towards peripheries forming moderately active seismic zones (Rao and Rao, 1984).

The WCGP is considered one of the most important tectonic features in the DVP. Sharp gravity field gradients (from $-50 \mathrm{mGal}$ to $-110 \mathrm{mGal}$ ) along the west coast (Kailasam et al., 1972), concentration of hot springs with high flow along WCGP (Raval, 1995; Ravi Sankar, 1988) with concentration of internal currents (Arora and Reddy, 1991) supplement to the anomalous nature and thermo mechanical behaviour of DVP. The study region also includes the Koyna-Warna region, a typical site of Reservoir Induced Seismicity (RIS) which has been experiencing earthquakes for the last 37 years (Gupta, 1992), and the Jawhar-Wada region with recently reported seismic activity.

\section{Monumentation and Observation Procedure}

Exposed bed rocks were chosen with unobstructed view of the sky and with non reflective environment as GPS sites. About $1 \mathrm{~cm}$ diameter and $6 \mathrm{~cm}$ deep hole was made and a stainless steel pin (non magnetic pins were used to enable absolute total magnetic field measurements for piezo-magnetic studies in coming years) of slightly less than that of above dimension was driven along with the adhesives. A fine dot of $0.5 \mathrm{~mm}$ is made on the pins to aid accurate measurements. These monuments which were made on vast expanses of bed rocks are considered to have least site instabilities.
Five WILD SR-299 nine channel dual frequency receivers were used in re-occupation mode. Microstripped omni directional (with $9 \mathrm{~cm}$ internal ground plate) GPS antennas were placed over the marks using tripods. The strategy of occupying the sites was such that the subsequent sessions contain at least one baseline common (known as frog leaping method) to enhance the precision and reliability of the network. The observations were made in eight 3-day sessions. At each site 36 hours of data have been collected for three campaigns during 1997-1999. To minimize the effects of troposphere, for each campaign, the data has been collected during winter when the humidity is very low. The sampling interval and elevation were fixed at $30 \mathrm{sec}$ and $15^{\circ}$ respectively throughout the survey.

\section{GPS Data Analysis}

The GPS data were organised into 24 hours segments covering a UTC day to facilitate the combination of data from some of the surrounding IGS sites; IISC, DGAR, BAHR, KIT3, LHAS, YAR1 to constrain the site co-ordinates. Then the data were processed using the GAMIT software developed at MIT and SIO (King and Bock, 1991) to produce estimates and an associated covariance matrix of station positions for each session with loose constrains on the parameters. To get a combined solution (site positions and velocities), all such covariance matrices are input to GLOBK which is a Kalman filter. The basic algorithms and a description of this technique are given in Herring et al. (1990) and its application to GPS data is in Feigl et al. (1993). By introducing global h-files, we have obtained coordinates and velocity vectors at each site in the ITRF96 reference frame (Boucher et al., 1998). Figure 1 shows the horizontal component of the velocity vectors with $95 \%$ confidence error ellipses. The horizontal components of these velocity vectors are further used to estimate the horizontal strain field by Least-Squares Prediction (LSP) method which is discussed below.

\section{Least-Squares Prediction Technique}

The Least-square prediction technique (LSP) has been developed by Moritz (1980) for the reduction of gravity data, and was applied to the crustal deformation data by Fujii and Xia (1993), and El-Fiky et al. (1997). The method is a corollary of the Least-Squares Collocation technique (LSC). The method was discussed in detail in El-Fiky et al. (1997) and in El-Fiky and Kato (1999). In the present study, the outline of the method is explained and the results of its application to the present field of study are shown.

In the LSP, the crustal deformation data $\mathbf{l}$ is assumed to be composed of systematic errors, tectonic signal $\mathbf{t}$ and noise $\mathbf{n}$ so that it is expressed by the following observation equation;

$$
\mathbf{I}=\mathbf{t}+\mathbf{n} .
$$

Here we assume that there is no systematic error in the data.

In the daily solution of GPS dense arrays, systematic baseline biases are removed in the daily baseline analysis, so that the resultant coordinates may be assumed to be free from systematic errors. Thus, the problem is to extract the signals at any location from $\mathbf{I}$ by some filtering technique, considering that the noise (n) is limited to only the site or adjacent local regions, and tectonic signals may have rather wider spatial 


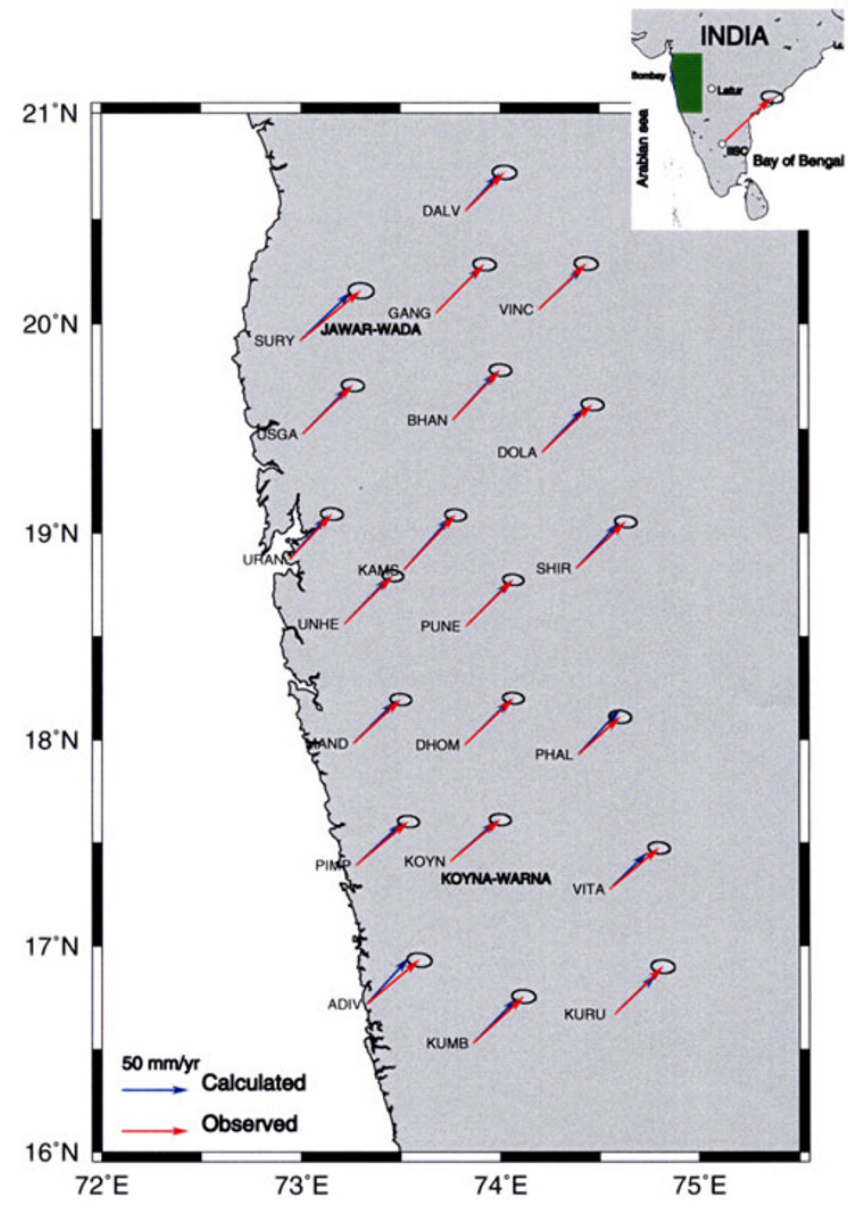

Fig. 1. Observed (red) and calculated (blue) horizontal velocity vectors at 21 sites in Deccan Valcanic Province, western India (shaded portion in the inset). The velocity vector for IGS site IISC (Bangalore) is shown in the inset.

correlations in nature (El-Fiky and Kato, 1999). Variancecovariance analysis of data is a good measure to find such spatial correlation. If we assume that the field is isotropic and homogeneous, the covariance of data is only a function of site distance "d" (e.g., El-Fiky et al., 1997). Such a function may be fitted by a simple mathematical function. Then we can reconstruct the signal at any arbitrary grid points (S) using this as such a fitted function, which is called the Empirical Covariance Function (ECF) (e.g., El-Fiky and Kato, 1999). We used a Gaussian function $\mathrm{C}_{l}(\mathrm{~d})=\mathrm{C}_{t}(0) \exp \left(-\mathrm{k}^{2} \mathrm{~d}^{2}\right)$, as ECF, where $\mathrm{C}_{t}(0)$ and $\mathrm{k}$ are constants. Two parameters $\mathrm{C}_{t}(0)$ and $\mathrm{k}$ are estimated from a covariance plot of the data. $\mathrm{C}_{t}(0)$ is the expected variance at the observation station and $\mathrm{C}_{n}(0)=\mathrm{C}_{l}(0)-\mathrm{C}_{t}(0)$ is considered as the noise component at the site. Finally, the defined Gaussian function $\mathrm{C}_{l}(d)$ is used to compose $\mathbf{C}_{s t}$, the covariance matrix between the data points and other grid points where signals are to be estimated. Once such ECF is obtained, we can estimate signal $\mathbf{S}$ at any arbitrary location by the following equation (El-Fiky et al., 1997):

$$
\mathbf{S}=\mathbf{C}_{s t} \mathbf{C}_{l}^{-1} \mathbf{l} .
$$

To estimate the crustal strains in GPS data for the period (1997-1999), we used horizontal velocity vectors shown in Fig. 1. The averages of velocities in the NS and EW compo-

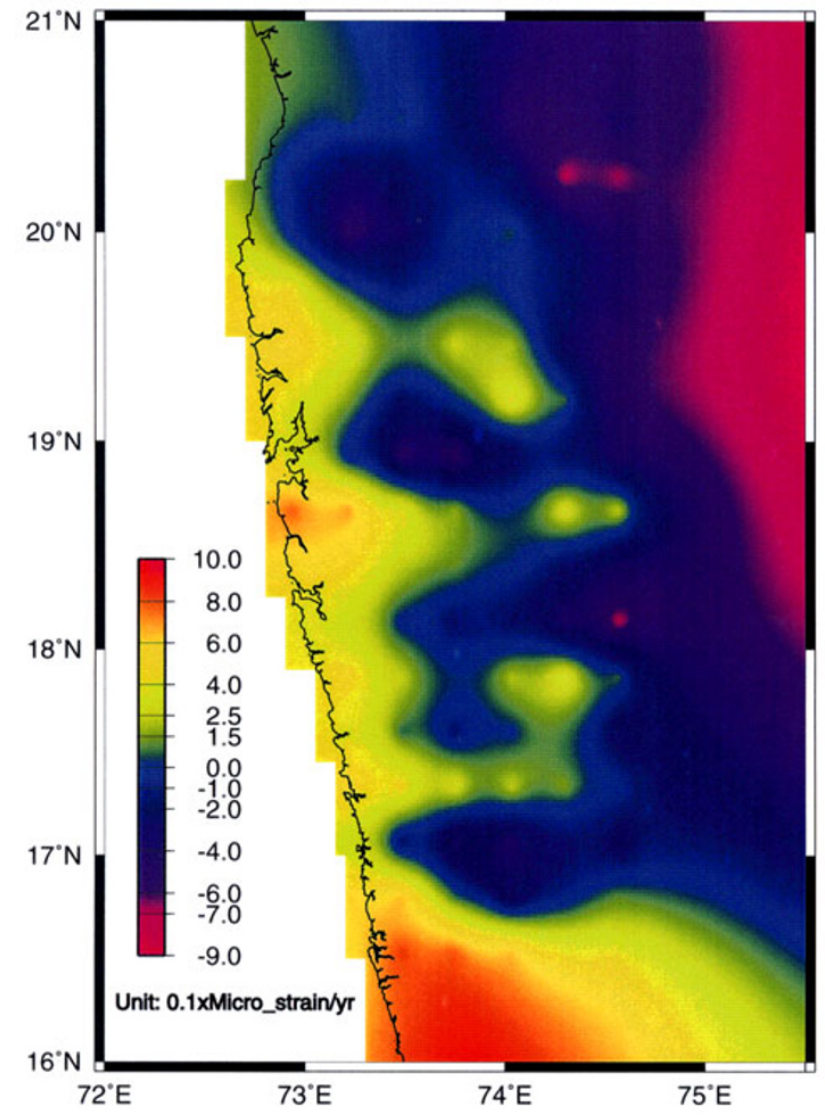

Fig. 2. Distribution of dilatational strain rate calculated from the velocity field shown in Fig. 1.

nents are subtracted separately from all of the site velocities to remove the systematic bias. Then, we applied the LSP as described above to each of the vector components (EastWest and North-South) independently. ECF for each of the components are fitted to the data. Then, ECFs are used to reconstruct displacement vectors (signal) at gridded points $(7 \mathrm{~km} \times 7 \mathrm{~km})$ of the studied region. Then estimated velocities at grid points are differentiated in space to obtain total crustal strains in this data period. Figures 2, 3, and 4 are the thus estimated dilatational strains, maximum shear strains, and directions of principal axes of strains, respectively.

\section{Results and Discussion}

The magnitude of the horizontal velocity vectors in ITRF96 is in the range of 40-60 mm/yr with an average of $51 \mathrm{~mm} / \mathrm{yr}$ in $\mathrm{N} 47^{\circ} \mathrm{E}$. The associated errors are about $3 \mathrm{~mm}$ and $2 \mathrm{~mm}$ in east and north components, respectively. The observed horizontal velocity vectors with error ellipses are shown in Fig. 1. In magnitude and the direction, the velocity vectors are comparable to IISC IGS site (inset of Fig. 1). The estimated average dilatational strain is about 0.4 micro strain/yr (Fig. 2). The average shear strain is also about 0.4 micro strain/yr (Fig. 3). The principal axes of strains shown in Fig. 4 indicate an extensional strain regime along the west coast and south of Koyna and Warna reservoirs, transcending into a region of compressive strain towards the interior of the shield area. These features also seen in the dilatation strain distribution in Fig. 2. The axes of compression swing from 


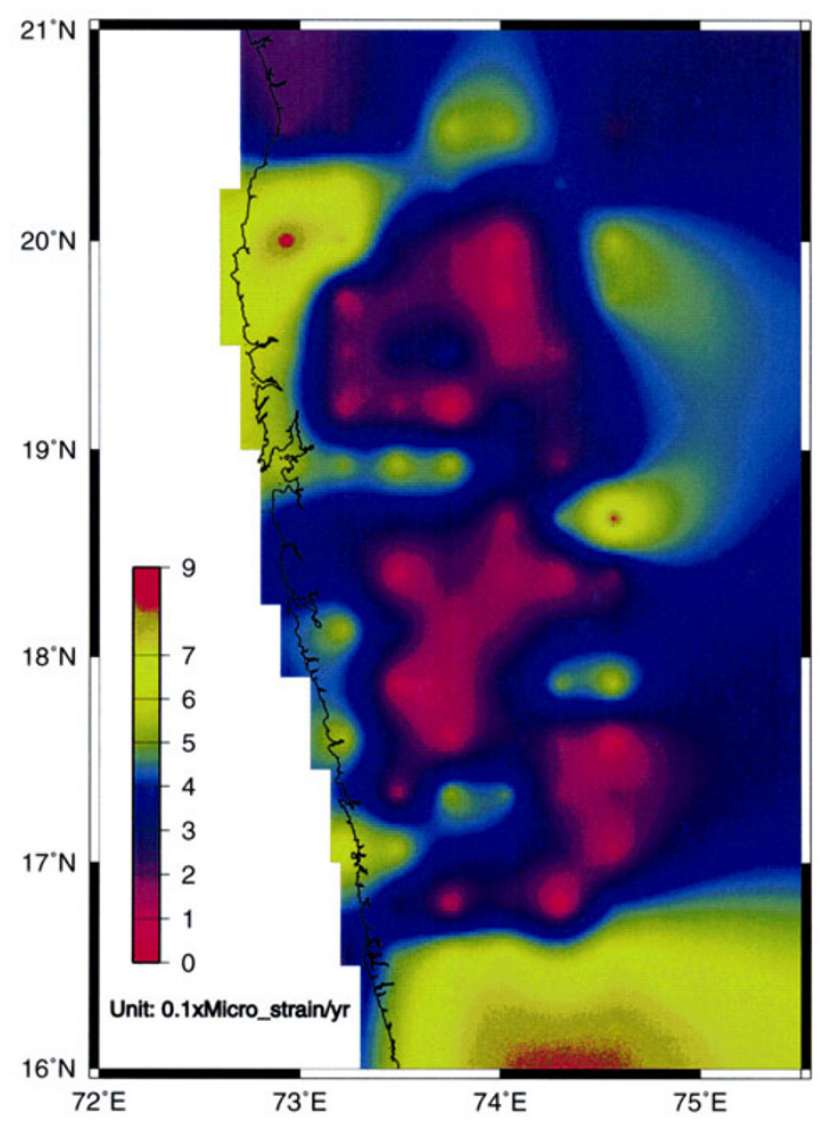

Fig. 3. Distribution of maximum shear strain rate calculated from the velocity field shown in Fig. 1.

EW to NS direction with increase in latitude.

The strain pattern in the study area seems to reflect the transmitted stress field due to the northward continental collision between the India and Eurasia plates along the Himalayan arc. The axes of stress $\left(\mathrm{S}_{\mathrm{Hmax}}\right)$ by Chandra (1977), Cloetingh and Wortel (1985), Rastogi (1992), Gowd et al. (1992), Rajendran et al. (1992) in NS to NNS directions indicate that the stress field generated by the above process has affected the entire peninsular shield and that the plate driving forces are mainly responsible for the observed tectonic stress field (Gowd et al., 1992; Talwani and Rajendran, 1991). The pattern of principal axes of compressive strain shown in Fig. 4 fit into the above concept. The tendency of these axes to swing from EW to NS direction indicates that towards north the region is more influenced by the India and Eurasia collision.

The extension regime coincides with WCGP. The NS trending parallel faults along WCGP were developed during the Quaternary period (Gubin, 1969), due to unequal upliftment of the western margin. These faults are seen to be a source of stress accumulation and a site of normal faulting resulting in EW extension due to block adjustment along the NS planes. In such regions, buoyancy-derived extensional stresses dominate the compressional stress field (Zoback, 1992). From simple physical models, England and Molnar (1991) calculated such forces and found that they can be of the same order as plate driving forces. In WCGP region, magnitude of such forces must be much higher as

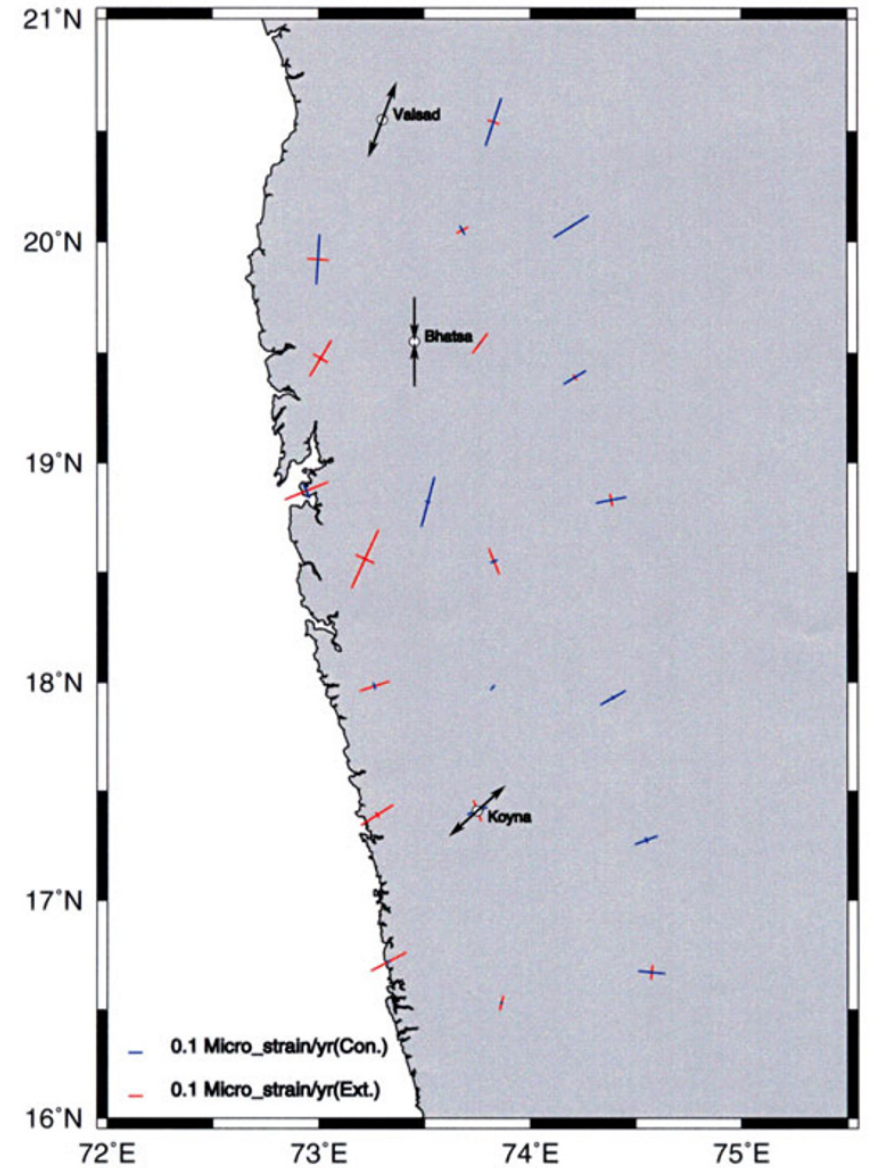

Fig. 4. Principal axes of strain at GPS sites corresponding to the dilatation strain rate shown in Fig. 2. Blue and red lines indicate the axes of compressional and extensional strain rates respectively. The axes of compression and tension (in black) at the sites with open circles are based on fault plane solutions (Rastogi, 1992).

they have to first nullify the compressive forces from plate driving forces and show up significantly.

The high dilatational strain field south of Koyna-Warna reservoir correlate with NW-SE trending fault system intersecting the major NNE-SSW to N-S feature. The fault plane solutions south of the study region (particularly near Koyna) by Scheidegger and Padale (1982) and Rastogi (1992) corroborate the directions of the principle axes of strain shown in Fig. 4. The fast velocity direction inferred from shear-wave splitting measurements and teleseismic time-term analysis (Rai et al., 1992) also correlate with principal axes of strain. Along the coast, the region of high shear strain seems to follow the lineament along which the gravity field abruptly changes from $-50 \mathrm{mGal}$ to $-110 \mathrm{mGal}$.

\section{Conclusions}

Velocity vectors (in ITRF96) obtained from 3 GPS campaigns during 1997-1999, indicate that the magnitude of the horizontal velocity of DVP is in the range of 40-60 mm/yr with an average of $51 \mathrm{~mm} / \mathrm{yr}$ in $\mathrm{N} 47^{\circ} \mathrm{E}$. The estimated dilatational strain and shear strain are both about 0.4 micro strain/yr in average. An extensional strain regime is observed along the west coast and south of Koyna and Warna reservoirs, transcending into a region of compressive strain towards the 
interior of the shield area. The extensional strain regime coincides with the WCGP and intersecting fault system south of Koyna-Warna reservoirs. And the compressional strain regime could possibly be correlated with the India-Eurasia collision forces in the NS to NNE-SSW direction. The principal axes of the strains correlate with the $\mathrm{S}_{\mathrm{Hmax}}$ directions obtained from other techniques such as borehole breakouts, hydraulic fracturing stress measurements, and earthquake focal mechanisms. No rigorous quantitative analysis is given as the density of the sites is not adequate. The exceptionally high values of strain rates particularly SW corner and east of the study region may be due to insufficient data for LSP and not to be taken into serious consideration.

Acknowledgments. This work forms the part of 'Seismological upgradation and related studies in Peninsular Shield' initiated by Department of Science and Technology (DST), Government of India. The financial support by DST is gratefully acknowledged. Sincere thanks are extended to Messrs. A. T. Deshmukh, B. D. Kadam, Atul Kulkarni, Ponraj, Amrithraj, Enperumal, Jeeva, and Panner Selvam for their efforts in collecting GPS data with the most care. The authors thank Dr. T. N. Gowd and Dr. N. Purnachandra Rao from NGRI, Hyderabad for their valuable suggestions. The authors C. D. Reddy and El-Fiky are thankful to Japan Society of Promotion of Science (JSPS) for awarding the JSPS Fellowship and facilitating the analysis of the data at the Earthquake Research Institute, University of Tokyo.

\section{References}

Arora, B. R. and C. D. Reddy, Magnetovariational study over seismically active area in the Deccan Trap Province of western India, Phys. Earth Planet. Inter, 66, 118-131, 1991.

Boucher, C., Z. Altamimi, and P. Sillard, Results and analysis of the ITRF96, IERS technical note 24, Observatory de Paris, 1998.

Chandra, U., Earthquakes of peninsular India-a seismotectonic study, Bull. Seism. Soc. Am., 67, 1387-1413, 1997.

Cloetingh, S. and R. Wortel, Regional stress field of the Indian plate, Geophys. Res. Lett., 12, 77-80, 1985.

El-Fiky, G. S. and T. Kato, Continuous distribution of the horizontal strain in the Tohoku district, Japan, deduced from least squares prediction, $J$. Geodynamics, 27, 213-236, 1999.

El-Fiky, G. S., T. Kato, and Y. Fujii, Distribution of the vertical crustal movement rates in the Tohoku district, Japan, predicted by least-squares collocation, J. Geodesy, 71, 432-442, 1997.

England, P. and P. Molnar, Inferences of deviatoric stress in actively deforming belts from simple physical models, Proc. R. Soc. London, 337, 151-164, 1991.

Feigl, K. L., R. W. King, T. A. Herring, and M. Rothacher, Space geodetic measurement of crustal deformation in central and southern California, 1984-1992, J. Geophys. Res., 98, 21677-21712, 1993.

Fujii, Y. and S. Xia, Estimation of distribution of the rates of vertical crustal movements in the Tokai district with the aid of least-squares prediction, J. Phys. Earth, 41, 239-256, 1993.

Gaur, V. K., Evaluation of seismic hazard in India towards minimizing earthquake risk, Current Science, 63, 324-335, 1994.

Goodwin, A. M., Precambrian Geology: The Dynamic Evolution of the
Continental Crust, 666 pp., Academic press, Great Britain, 1991.

Gowd, T. N., S. V. Srirama Rao, and V. K. Gaur, Tectonic stress field in the Subcontinent, J. Geophys. Res., 97, 11879-11888, 1992.

Gowd, T. N., S. V. Srirama Rao, and K. B. Chary, Stress field and seismicity in the Indian shield: effects of the collison between India and Eurasia, $P A G E O P H$, 146, 503-531, 1996.

Gubin, I. E., Seismic zoning of the western margin of the Indian peninsula in Maharashtra state, UNESCO, serial no. 1519/BMS.RD/SCE, Paris, 1969.

Gupta, H. K., Reservoir Induced Earthquakes, 355 pp., Elsevier Scientific Publishing Co., Amsterdam, 1992.

Gupta, H. K., The deadly Latur earthquake, Science, 262, 1666-1667, 1993.

Herring, T. A., J. L. Davis, and I. I. Shapiro, Geodesy by radio interferometry: The application of Kalman filtering to the analysis of very long baseline interferometry data, J. Geophys. Res., 95, 12561-12581, 1990.

Kailasam, L. N., Geophysical and geodynamical aspects of the Maharashtra earthquake of September 30, 1993, Current Sci., 65, 736-739, 1993.

Kailasam, L. N., B. G. K. Murthy, and A. Y. S. Chayanulu, Regional gravity studies of Deccan areas of Peninsular India, Current Sci., 41, 403-407, 1972.

King, R. W. and Y. Bock, Documentation for the MIT GPS analysis software, Mass. Inst. of Technol., Cambridge, 1991.

Moritz, H., Advanced Physical Geodesy, 500 pp., Herbert Wichmann Verlag, Karsvuhe, 1980.

Naqvi, S. M. and J. J. W. Rogers, Precambrian Geology of India, 238 pp., Oxford Press, New York, 1987.

Paul, J., F. Blume, S. Jade, V. Kumar, P. S. Swati, M. B. Ananda, V. K. Guar, Roland Burgmann, Roger Bilham, B. Namboodri, and Dave Mencin, Microstrain stability of Peninsular India 1864-1994, Proc. Indian Acad. Sci. (Earth Planet. Sci.), 104, 131-146, 1995.

Rai, S. S., D. S. Ramesh, D. Srinagesh, K. Suryaprakasam, G. Mohan, P. V. S. S. Rajagopala Sarma, and Y. Satyanaraya, Seismic tomography of the south Indian shield, Current Sci., 62, 213-226, 1992.

Rajendran, K., P. Talwani, and H. K. Gupta, State of stress in the Indian subcontinent: A review, Current Sci., 62, 86-93, 1992.

Rao, B. R. and P. S. Rao, Historical seismicity of Peninsular India, Bull. Seism. Soc. Am., 74(6), 2519-2533, 1984.

Rastogi, B. K., Seismotectonics inferred from earthquakes and earthquake sequences in India during the 1980s, Current Sci., 62, 101-108, 1992.

Raval, U., Seismicity of the Koyna region and regional tectonomagmatism of the western margin (India), Pure Appl. Geophys., 145, 175-192, 1995.

Scheidegger, A. E. and J. G. Padale, A geodynamic study of Peninsular India, Rock Mechanics, 15, 209-241, 1982.

Seeber, L., G. Ekstrom, S. K. Jain, C. V. R. Murthy, N. Chandak, and J. G. Armbruster, The Killari earthquake in central India: A new fault in Mesozoic basalt flows?, J. Geophys. Res., 101, 8543-8560, 1996.

Sankar, R., Heat flow map of India and discussions on its geological and economic significance, Indian Minerals, 42, 89-110, 1988.

Singh, A. P. and D. M. Mall, Crustal accretion beneath the Koyna coastal region (India) and Late Cretaceous geodynamics, Tectonophysics, 290, 285-297, 1998.

Talwani, P. and K. Rajendran, Some seismological and geometric features of intraplate earthquakes, Tectonophysics, 186, 19-41, 1991.

Zoback, M. L., First and second order patterns of stress in the lithosphere: The world stress map project, J. Geophys. Res., 97(B8), 11703-11728, 1992.

C. D. Reddy (e-mail: cdreddy@eri.u-tokyo.ac.jp), G. El-Fiky, T. Kato, S. Shimada, and K. V. Kumar 